Archived version from NCDOCKS Institutional Repository http://libres.uncg.edu/ir/asu/

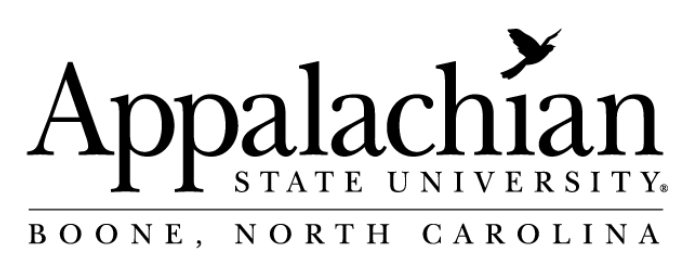

\title{
Context Is Key: The Media Role in Shaping Public Perceptions about Environmental Issues
}

by: Kristan Cockerill

Cockerill, K. 2002. Context is Key: The Media Role in Shaping Public Perceptions about Environmental Issues. Environmental Practice 4(2): 107-113. (June 2002) Published by Cambridge University Press (ISSN: 1466-0474). DOI:10.1017/S1466046602021117 Publisher's version available from Cambridge Journals Online at: http://journals.cambridge.org/action/displayJournal?jid=ENP 


\section{Context Is Key: The Media Role in Shaping Public Perceptions about Environmental Issues}

\author{
Kristan Cockerill
}

Many environmental professionals are reluctant to interact with the media, often because of a negative experience and the perception that poor coverage can affect environmental programs and policies. Using a case study of media coverage related to the Albuquerque, New Mexico, water supply, this research documents that indeed, the media can influence public opinion and this can have policy and program implications. This research compared media coverage about various water customers (residential, commercial, institutional, industry) to public perceptions about who uses the most water and to actual use levels reported by the city. The results show that coverage in terms of numbers of articles, article content and language, as well as page placement, correlates with public perceptions about which customers use the most water, and that these perceptions do not well match actual use levels. A key point for this work is that although the information presented within the individual articles was largely accurate, it was the pool of coverage assessed as a whole that misrepresented water use levels. This report also provides key steps that environmental professionals can take to help improve overall coverage and help raise the potential for public perception to better match actual data.

Environmental Practice 4:107-113 (2002)

\footnotetext{
$\mathrm{A}$ nswering the phone to find a reporter at the other end can be a stressful experience for many environmental professionals. Most environmental scientists and engineers recognize that media coverage can alternately be a blessing and $a$ bane to their programs and policies and that how they respond to a reporter's call can have far-reaching ramifications. The power that the media possess is recognized, and therefore many agencies and corporations have internal
}

policies dictating who can speak with journalists. These policies often originate after a negative experience with the media. Over the past several years I have spoken with numerous environmental scientists and policy makers about media coverage of various issues, and almost every individual shared an anecdote relating a negative experience. While often quite critical of media coverage, these individuals also know that ignoring the media can be detrimental. The professionals interviewed intuitively recognize the influence the media can wield in terms of public perception and public response to environmental concerns. Reflecting their recognition of media power (and perhaps potential?), several of the individuals most critical of media coverage still maintain "clip files" of all the news articles relevant to their particular work. These critics acknowledged that they use these files as a chronology of various events and to track policy developments.

What these professionals have sensed intuitively or learned through personal experience about media influence has also been documented in communication-based research. $\mathrm{Nu}$ merous scholars have studied the role that media play in our public lives. Past research has developed an agenda-setting theory, which tells us that the issues the media cover heavily and widely will be the issues that readers declare most important (Cook et al., 1983; McCombs and Shaw, 1972; McLeod, Becker, and Byrnes, 1974). While agenda-setting theory traces its roots to how the media has helped shape political elections, relevant research has expanded to assess a wide variety of public issues. There is evidence that the media do play a significant role in influencing public opinion about environmental issues, and that public views have generated policy attention (Neuzil and Kovarik, 1996; Sachsman, 1996).

In addition there is a growing body of work studying how the media cover science and environmental issues. In general, findings reveal that there are significant language and cultural barriers between the disciplines of science (obviously key for much environmental work) and journalism.

Affliation of author: Dowbiggin Limited, Albuquerque, New Mexico

Address correspondence to: Kristan Cockerill, Senior Policy Analyst, Dowbiggin Limited, PO Box 93054, Albuquerque, NM 87199; (fax) 505-8218010; (e-mail) kmcockerill@dowbiggin.com.

(C) 2002 National Association of Environmental Professionals 
The goals and practices in these fields are quite distinct, and one result is that there are often substantial errors in media stories about science and/or environmental hazards (Hartz and Chappell, 1997; Nelkin, 1995; Singer and Endreny, 1993). In fact, much of the literature related to science in the news has focused on accuracy in reporting.

While ensuring accuracy within individual stories is important, another crucial factor is considering the total body of coverage and the context provided for a particular issue. Scientists interviewed for this project noted that too many articles do not place an issue in context and too often seem to reflect a reporter's bias or preconceived ideas. The work reported here is based on a case study of media coverage about the water supply for Albuquerque, New Mexico. It ties research about how an issue is covered to agenda-setting theory by questioning whether the way an issue is covered affects public perception about that issue, which in turn may impact public policy decisions.

This research provides a starting point for environmental professionals to become more aware of communication issues and the implications that accurate, but perhaps incomplete, media coverage may have for environmental policy or management decisions. Better understanding of how the media currently cover environmental issues may help identify methods for working with the media to present more context-appropriate coverage. Ideally, this will lead to a better-informed public, and hence an improved atmosphere for making environmental decisions.

\section{Case Study Background}

For the arid American Southwest, water concerns continue to rise on policy agendas as the perceived supply falls. Albuquerque is no exception, and 1993 was a watershed year for changing policies and perceptions about the water supply there. In August 1993, the United States Geological Survey (USGS) published a report concluding that the Middle Rio Grande aquifer, which provides all drinking water for the city and surrounding areas, was not as extensive as had been popularly believed (Thorn, McAda, and Kernodle, 1993). This set off a stream of media coverage, scientific studies, and policy debates concerning the water supply and potential ramifications for people and the environment. In 2002, policy makers continue to debate and develop conservation programs and water supply options for Albuquerque and the surrounding region. This project assessed how the first several years of media coverage following the USGS report may have influenced public perception about the water supply, and who uses how much water in Albuquerque. In this case, the individual articles were largely accurate concerning water use and conservation proposals. The coverage as a whole, however, can be interpreted as misrepresenting the overall situation. This coverage seems to have influenced public perception about water use in the area, and this may well have significant future policy ramifications.

\section{Method}

This project employed a content analysis approach to document specific information from individual stories, and then to analyze the complete set of articles about the water supply issue. Using a microfiche index for the Albuquerque Journal and the Albuquerque Tribune (the primary newspapers in central New Mexico), I identified all articles from 1993 through 1997 under the general heading "water," as well as under the sub-headings "conservation" and "rights." Additionally, researchers at the USGS loaned me their clip files that included numerous relevant articles not listed in the Journal/Tribune index. This analysis included all articles focused on research and policy related to the water supply, including all types of coverage from "hard news" to op-ed pieces and letters to the editor. This article search provided 328 articles.

For each article basic information was recorded, including publication date, length, author, and page placement. For the work documented here, I reviewed each headline, subhead and first column of text, to determine if the article focused on a particular water user (industry, institutional, residential, commercial) or issues related to a particular user group. These are the billing categories for Albuquerque Public Works, which provides water to customers connected to city wells.

The categories are defined as follows:

- Residential use includes individually metered housing units;

- Commercial use is for businesses, including restaurants, hotels, and apartment complexes;

- Institutional use includes local, state and federal buildings as well as museums, hospitals, schools, parks, and street medians; and

- Industry users are large-scale manufacturing entities.

In addition to these public works customer groups, a category was created for articles that discussed all users. This "all" category includes articles that provided an update on the conservation program and hence covered all users who 
receive a city water bill. There were a total of 151 articles focused on one of the five categories described. For each of these customer-focused articles I noted key words and phrases used to characterize water use for that particular user group.

After completing the content analysis, I reviewed the results from a 1999 City of Albuquerque Water Conservation Survey of Consumers. An Albuquerque research firm, Research \& Polling, Inc. (1999), surveyed 609 randomly selected adults who receive water bills in Albuquerque about their perceptions and opinions concerning the water supply and conservation programs. I compared the results from my content analysis to the survey results to identify potential correlations between the media coverage and public perceptions about the water customer groups.

\section{Results}

Of the 151 articles assessed, 51 focused on residential use, 37 each on institutional and industrial use, eight on commercial use, and 18 covered all categories (Figure 1). The 1999 Albuquerque water customer survey asked respondents to identify which of the four user groups they believed used the most water. Figure 2 shows that industry received the most votes as largest user, followed by residences, institutions, and commercial users. Finally, Figure 3 shows actual use levels in 1998 for each of the customer categories.

Clearly, Figures 1 and 2 are much more similar to each other than either of them is to the pie chart in Figure 3 showing actual use levels for each group. Most obvious, $37 \%$ of the surveyed public believe that industry is the highest user and $25 \%$ of the media coverage focused on industry. In reality, industry accounts for only $3 \%$ of the withdrawals from $\mathrm{Al}$ buquerque wells. Commercial use provides another good example of the ties between public perception and media coverage and the disconnect with actual use rates. Only $5 \%$ of the media articles focused on commercial use and only $10 \%$ of survey respondents said that commercial entities were the highest users. Actually, commercial use is the second highest category, accounting for $22 \%$ of Albuquerque's withdrawals. This suggests that the number of articles devoted to the various users influenced perceptions about actual use levels.

The data also reveal that the specific content and the language used to describe or discuss each of these groups may be more powerful than the number of articles in influencing public perceptions about water use in Albuquerque. The industry category reflects the greatest discrepancy among



Figure 1. Articles devoted to the Albuquerque Public Works water customer categories in Albuquerque newspapers, 1993-1997 $(n=151)$.

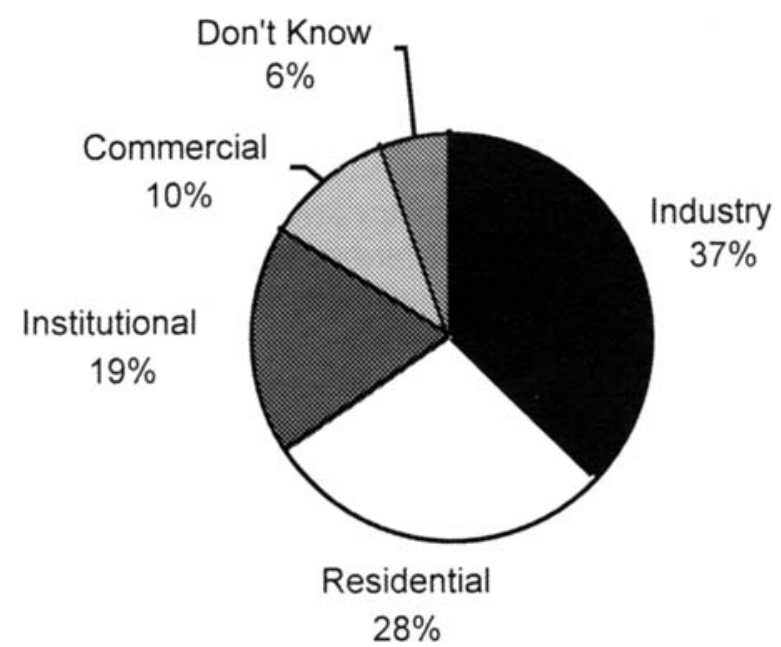

Figure 2. Public response to the question, "There are four groups of water customers: residential, which is mostly single family homes; industrial manufacturers that produce products; commercial customers such as restaurants, small businesses, and apartment complexes; and institutional customers, such as city, state, and federal governments and hospitals. Which of these four customer groups do you think is the largest consumer of water?" $(n=609)$.

public perception, media coverage and the reality of who withdraws how much water. The majority of news coverage about industrial use focused on water rights and industry attempts to acquire more water. Specifically, there was significant coverage in 1997 about computer chip manufacturer Intel's quest to purchase water rights from local farmers and landowners. The articles pitted industrial use against the more traditional agricultural uses. Additionally, just before the stream of articles discussing Intel's bid for rights, both papers ran articles about a 1997 report which, 


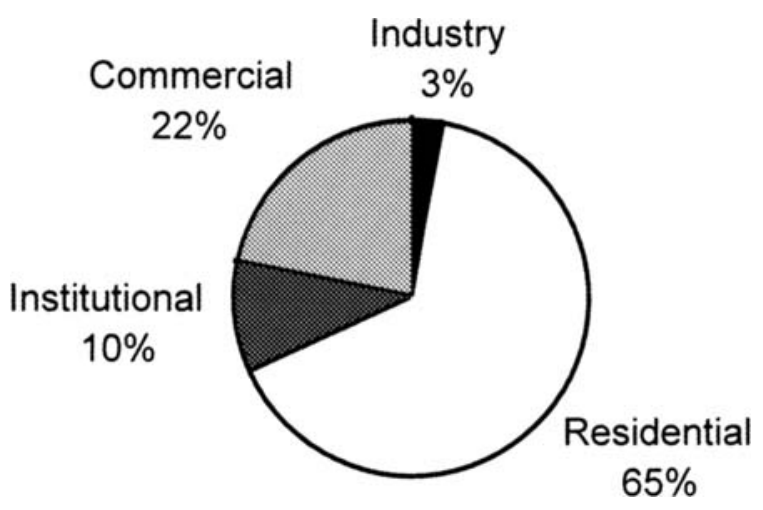

Figure 3. Actual water withdrawals by Albuquerque Public Works customers, 1998.

according to an Albuquerque Tribune story, concluded that "people don't realize how thirsty and how toxic manufacturing plants are" (Holmes, 1997). The specific information provided in the industry-related articles included references to the vast quantities of water that the plants use daily. Several articles noted that Phillips Semiconductor uses one million gallons per day, and Intel uses three to four million gallons per day, and some articles refer to these industries as "the largest user in the area" or "the largest user in the city." This language, and the large numbers involved, could readily generate the impression that industry must not only be the largest single customer, but as a category must be $\mathrm{Al}$ buquerque's most significant user. Another relevant point is that much of the newspaper coverage about industry focused on Intel, which has its own wells and hence is not an Albuquerque water customer. Of course, there is a single aquifer from which Albuquerque and Intel draw their water. However, if Intel's withdrawals were included in the Albuquerque water customer statistics, industry would still account for only $6 \%$ of the total and would remain the smallest user category. The heavy coverage about Intel helps to further explain why public perceptions about industry use are so far from Albuquerque's actual use data, and may also have contributed to Intel's inability to secure additional water rights at that time.

The residential use coverage flowed differently than the industry-focused coverage. The 51 articles devoted to residential use showed the greatest diversity in focus, although almost half were about various aspects of conservation efforts, including xeriscaping (landscaping with native plants) and the program to provide rebates to homeowners who install low-flow toilets. The second largest group of residential use articles provided information about rate hikes and water-wasting ordinances. The residential articles tended to focus on what could be done to reduce use, and the impact that reduction efforts can have. The articles often specifically mentioned that Albuquerque households average about 250 gallons per person per day and referred to the city's goal to reduce use to 175 gallons per person per day. Compared to the millions of gallons per day attributed to industry, these household numbers may have created the misperception that residential use must be less than industrial use. One explanation for this is that the general public is largely innumerate and the media do a poor job covering quantitative information (Kolata, 1997). The average reader may not make the connection that it requires only 4,000 of the approximately 385,000 people in Albuquerque (using 250 gallons per day) to equal the one million gallons per day reported for Phillips Semiconductor.

Another factor likely contributing to the misconception about industry's use, especially vis-à-vis residential use, are the articles in the "all" category. These articles discussed the city's conservation program and reported how various user groups were performing. In general, I found these articles confusing. The data sometimes compared one month to the previous month, one year to the previous year or the current month with that same month in the previous year. The flurry of statistics did little to provide context for the conservation program or use patterns. Most relevant to public perception, however, were the actual numbers reported for the customer categories. In 13 of the 18 reports, industry use increased, often by double-digit percentages. In 10 of the 18 reports residential use decreased, sometimes by more than $10 \%$. Although the media did a good job of noting that industry accounts for only $3 \%$ of the city's total water accounts, the double-digit increases in industrial withdrawals may have been the more compelling statistic in guiding public perception. Again, the numerical illiteracy factor likely plays a role here. Readers may not understand, or take the time to consider, that a $10 \%$ increase for industry using 1 million gallons per day is still significantly less total water than the billions of gallons used in residences, even if residential use decreased by $10 \%$. Additionally, the language used in these "all" articles is highly relevant to documenting the relationship between media coverage and public perception. Residential use headlines often featured phrases like, "Residents Led Water Reduction ..." or "Residents Rush to Toilet-Rebate Program." Industry articles, on the other hand, were more likely to include phrases such as, "Report: Intel Uses Too Much Water" and "Intel Quest for Water Taps Doubts." 
Media coverage of the institutional and commercial categories also correlated well with public perceptions about those categories. There were 37 articles focused on institutional use. A majority of these articles criticized the city's water use and characterized the city as wasteful. For example, a few articles referred to the city as a "water guzzler." Several editorials and opinion pieces suggested that the city should not be asking residents to conserve until the city does a better job of conserving. The very first article I analyzed included a subhead noting that, "The city's Arroyo del Oso Golf Course uses as much water in a year as 2,600 people would use at home and work in that time" (Davis, 1993). Another article appearing in the conservation program's early days included the headline and subhead, "Leaks Squander Water: Line Breaks Undercut Conservation Message" (McCutcheon, 1994). The tone and language used in these articles may explain why $19 \%$ of the survey respondents perceived institutional customers to be the highest users, when in fact they account for only $10 \%$ of Albuquerque's aquifer withdrawals and are the second lowest water user.

Of the eight articles on commercial use, four were about businesses receiving conservation awards or implementing conservation programs. The small number of articles that focused on commercial use suggests that the news outlets do not see it as a priority. This, combined with the focus on business as conserver, likely contributed to few survey respondents stating that commercial customers are the largest city user, even though they actually use more than the institutional entities, and much more than industry, within the city.

The commercial articles also provide a good example of another factor that likely influences public perceptionwhere in the paper the articles appeared. Article placement reflects both the topic and how newsworthy editors believe the article to be. Of the eight commercial articles, five were in the business pages, typically not in section A. Only one commercial article was a front-page story. Residential and industry articles, however, were quite prominent in the first section. Forty-five percent of the residential articles appeared on the front page, and $41 \%$ of the industry-focused articles were front-page news. Institutional stories were less common on the front page ( $32 \%$ ), but $49 \%$ of them were in Section A. Casual readers may see only front-page stories. Even if they read the entire paper, readers may weigh frontpage issues more heavily when they assess importance, as most readers are well aware that what is deemed most newsworthy is featured earlier in the paper.

\section{Discussion and Recommendations}

These data suggest that there is a relationship between media coverage and public perception about water use in $\mathrm{Al}$ buquerque. The number of articles devoted to the various user categories, the content and language used in those articles, and the page placement all correlate well with public perceptions about Albuquerque's water customers. In this case study, the content and language used, as well as page placement, were perhaps more important than the number of articles devoted to a particular topic. For example, articles discussing residential water use were the most numerous, accurately reflecting where residential use ranks among water customers. Articles featuring industry use were less common, but the tone and content of the articles combined with the probable high rate of innumeracy among readers led survey respondents to conclude that industry is the single largest user. Interestingly, industry and institutional focused articles had equal representation in the number of stories, and both featured relatively negative coverage about these customer categories. Industry articles, however, were more likely to appear on the front page, and the numerical data reported may have swayed public perception to believe that industry is the largest user.

This relationship between media coverage and public perception is crucial for environmental practitioners who manage environmental programs or develop policy, and who may have to justify — or at least explain — policy issues and management decisions to the public. In this case study, for example, raising homeowner water rates to encourage conservation may make sense based on who actually uses the most water in Albuquerque, but residential rate hikes have historically met strong public resistance. The public perceptions about who uses the most water are likely a driving force in rate hike debates. Of course, other factors influence public attitudes about policy choices, especially those with personal economic implications, but the data here suggest that the media coverage may allow homeowners to believe that they are justified in saying that raising rates would be unfair to them.

In such complex and/or controversial cases, environmental professionals may be able to avoid or reduce conflict related to policy decisions if they are aware of the role that media coverage may be playing in framing issues and policy choices. Taking this a step further, environmental professionals can play a role in helping to improve the media coverage, which in turn will influence how an issue is framed and characterized. As noted in the introduction, the con- 
cern in this case study was not the accuracy of individual bits of information, but an issue of context for a whole pool of coverage. How the media portray quantitative information is often quite relevant to establishing context for an environmental concern, and this study highlights the need to provide meaningful comparisons. Again, environmental professionals have a role to play in helping journalists improve how they report numerical data.

For many environmental professionals, especially scientists and engineers, working with the media may not be something that comes naturally to them, nor was it likely part of their formal education. On the other side, few journalists have any formal training in fields relevant to much environmental work. There are real language and discipline-based cultural barriers between journalists and many environmental professionals. Working to reduce or eliminate these barriers in order to generate better media coverage will require effort from both environmental professionals and journalists. In a fascinating survey of 1,400 scientists and journalists assessing how they perceive each other and media coverage, Hartz and Chappell (1997) found some agreement among both groups that there is significant room to improve science coverage. They also found willingness from both sides to work together toward that end. Interestingly, their survey revealed that scientists and engineers say they are willing to talk to media, but $26 \%$ of them had "never been interviewed or written about in a science story during their entire career!"

To avoid error and the larger concern about misrepresentation in environmentally relevant reporting, it is imperative that environmental professionals attempt to work with their local media. Within the field of risk communication, as well as more general research related to science in journalism, there is a substantial body of work providing recommendations for improving media coverage (see, especially, Hartz and Chappell, 1997; Sandman, Sachsman, and Greenberg, 1987). Many of the suggestions for effective risk communication and for improving general science coverage are quite relevant to environmental policies and programs, even in non-risk situations. The following recommendations flow from an amalgamation of communication-based literature, as well as my own experiences in reviewing media coverage and interacting with reporters and environmental scientists.

\section{Speak the Language}

A classic complaint from journalists is that scientists cannot effectively communicate their knowledge. Learning to speak with journalists without using acronyms or jargon is essential. Remember, most local, and even many national, journalists are generalists. A reporter may well cover a car crash in the morning, your environmental issue at lunch and a school board meeting that evening. Most reporters will not have the depth of knowledge you do and more importantly, their readers will not likely have any education or experience with the environmental issue being reported. The reporter's job is to absorb complex information and make it interesting and understandable to their readers. Helping the reporter to develop an appropriate metaphor or graphic to illustrate an issue can greatly improve coverage and hence reduce potential misperceptions. Assisting reporters in making numerical data clear through examples or graphics may be particularly valuable. While learning to communicate effectively with and for journalists is key to increasing accuracy within individual articles, it can also help ensure that the individual articles flow together to form a pool of coverage that well represents the complexity and context of the program or issue.

\section{Establish a Relationship}

The most productive step for generating consistently accurate and contextual coverage is for environmental professionals to reach out to reporters and their editors. Become a reliable source and resource for reporters. Journalists typically work under severe time constraints and the ability to contact respected and reliable sources on short notice is critical to responsible reporting. Fostering a relationship enables both you and the journalist to begin to understand the culture and language of your respective disciplines. Additionally, if you and a reporter do develop a rapport, editors may be more likely to consistently assign that reporter to environmental stories. This allows you to help the reporter appreciate an issue's full context and to put individual stories within a larger frame.

\section{Be a Voice}

In addition to working with reporters, environmental professionals can make tremendous contributions to improving the total body of coverage by agreeing to write opinion pieces for editorial pages. This is, of course, not a panacea for poor coverage, and depending on the particular issue, this may not be appropriate or advisable. For example, having an environmental professional from industry write an opinion piece supporting company requests for additional water rights is on its face self serving. Even if all the data featured in the piece are accurate, many readers will discount the information. On the other hand, having an in- 
dustry environmental professional write a more generalized article about water systems not linked with a controversial issue may be more widely accepted. In this way editorials can integrate relevant scientific information into public perceptions about general water concerns.

The Public Relations Society of America has developed a National Credibility Index documenting that who the public perceives to be a credible information source can vary by topic. Their general index, however, shows that teachers typically receive high credibility ratings (Public Relations Society of America, 2001). Additionally, risk communication research has shown that educators, especially from local institutions, are often trusted sources (Covello, 1994; Jenkins-Smith, Barke, and Herron, 1994). This suggests that environmental professionals within academia may be crucial voices to help readers better understand specifics, such as numerical information, as well as to better appreciate the context within which any environmental issue sits. While there is no silver bullet for improving coverage, having the environmental professional voice featured regularly in the media can help ensure more rich and complete coverage.

\section{Conclusion}

While some of the recommendations provided here appear to be common sense, they are too often ignored. At other times, efforts to work with the media may have been sidetracked by a negative experience. Overcoming previous negative experiences or stereotypes is a difficult and timeconsuming process. Without better communication among environmental professionals and journalists, however, we will continue to see coverage that generates misperceptions and creates situations ripe for poor decision making. The case study highlighted here and the recommendations for environmental professionals to help improve coverage are intended to begin eliminating barriers. As journalism professor Travis Linn (2000) has noted, it is important to realize that when reporters cover science related stories (like the environment) and they get something wrong, it is not malice or prejudice, as scientists often believe, but a product of ignorance and incompetence relevant to the subject. Environmental professionals have the ability to help replace some of this ignorance with understanding, and incompetence with skill.

\section{References}

Cook, F. L., T. R. Tyler, E. G. Goetz, M. T. Gordon, D. Protess, D. R. Leff, and H. L. Molotch. 1983. Media and Agenda Setting: Effects on the Public,
Interest Group Leaders, Policy Makers, and Policy. Public Opinion Quarterly $47: 16-35$.

Covello, V. 1994. Handbook for the Environmental Risk Communication and Public Dialogue Workshop. Handout of speaker's notes from a Department of Defense internal workshop.

Davis, T. 1993. Water Guzzlers: City Hall Urges Conservation While It Drinks Deeply. Albuquerque Tribune June 25:A1.

Hartz, J., and R. Chappell. 1997. Worlds Apart: How the Distance Between Science and Journalism Threatens American's Future. First Amendment Center, Nashville, TN, 174 pp.

Holmes, S. M. 1997. High-Tech Centers Tough on Water, Report Charges. Albuquerque Tribune June 7:A3.

Jenkins-Smith, H. C., R. P. Barke, and K. G. Herron. 1994. Public Perspectives of Nuclear Weapons in the Post-Cold War Environment. Institute for Public Policy, University of New Mexico.

Kolata, G. 1997. Understanding the News. In Why Numbers Count, L. Steen, ed. New York College Examination Board, New York, 23-29.

Linn, T. 2000. Journalists: Standing Between Scientists and the Public. Presentation at the Geological Society of America Annual Meeting, Reno, NV, November 9-18.

McCombs, M. E., and D. L. Shaw. 1972. The Agenda-Setting Function of Mass Media. Public Opinion Quarterly 36(2):176-187.

McCutcheon, C. 1994. Leaks Squander Water: Line Breaks Undercut Conservation Message. Albuquerque Journal September 24:A1, A10.

McLeod, J. M., L. B. Becker, and J.E. Byrnes. 1974. Another Look at the Agenda-Setting Function of the Press. Communication Research $1(2): 131-165$.

Nelkin, D. 1995. Selling Science: How the Press Covers Science and Technology. W. H. Freeman and Company, New York, 217 pp.

Neuzil, M., and W. Kovarik. 1996. Mass Media and Environmental Conflict: America's Green Crusades. Sage Publications, Thousand Oaks, CA, 243 pp.

Public Relations Society of America (PRSA). 2001. National Credibility Index. http://www.prsa.org/nci/nci/html. Accessed 5 July 2001.

Research \& Polling, Inc. 1999. City of Albuquerque Water Conservation Survey of Consumers, June.

Sachsman, D. B. 1996. The Mass Media "Discover" the Environment: Influences on Environmental Reporting in the First Twenty Years. In The Symbolic Earth, J. Cantrill and C. Oravec, eds. University Press of Kentucky, 241-256.

Sandman, P., D. Sachsman, and M. Greenberg. 1987. The Environmental News Source: Informing the Media during an Environmental Crisis. Risk Communication for Environmental News Sources, Rutgers University, New Brunswick, NJ, 143 pp.

Singer, E., and P. Endreny. 1993. Reporting on Risk: How the Mass Media Portray Accidents, Diseases, Disasters and Other Hazards. Russell Sage Foundation, New York, 244 pp.

Thorn, C. R., D. P. McAda, and J. M. Kernodle. 1993. Geohydrologic Framework and Hydrologic Conditions in the Albuquerque Basin, Central New Mexico. US Geological Survey Water-Resources Investigations Report 934149, $106 \mathrm{pp}$.

Submitted July 12, 2001; revised January 24, 2002; accepted February 1, 2002. 